\title{
Testing UAV-derived topography for hydraulic modelling in a tropical environment
}

\author{
M. Mazzoleni ${ }^{1,2}$ (D) P. Paron ${ }^{3} \cdot$ A. Reali $^{4} \cdot$ D. Juizo ${ }^{5,6} \cdot$ J. Manane $^{7} \cdot$ L. Brandimarte $^{4}$
}

Received: 9 August 2019 / Accepted: 23 April 2020 / Published online: 7 May 2020

(c) The Author(s) 2020

\begin{abstract}
The past few years have seen the raise of unmanned aerial vehicles (UAV) in geosciences for generating highly accurate digital elevation models (DEM) at low costs, which promises to be an interesting alternative to satellite data for small river basins. The reliability of UAV-derived topography as input to hydraulic modelling is still under investigation: here, we analyse potentialities and highlight challenges of employing UAV-derived topography in hydraulic modelling in a tropical environment, where weather conditions and remoteness of the study area might affect the quality of the retrieved data. We focused on a stretch of the Limpopo River in Mozambique, where detailed ground survey and airborne data were available. First, we tested and compared topographic data derived by UAV $(25 \mathrm{~cm})$, RTK-GPS (50 cm DEM), LiDAR (1 m DEM) and SRTM (30 m DEM); then, we used each DEM as input data to a hydraulic model and compared the performance of each DEMbased model against the LiDAR based model, currently used as benchmark by practitioners in the area. Despite the challenges experienced during the field campaign — and described here-, the degree of accuracy in terrain modelling produced errors in water depth calculations within the tolerances adopted in this typology of studies and comparable in magnitude to the ones obtained from high-precision topography models. This suggests that UAV is a promising source of geometric data even in natural environments with extreme weather conditions.
\end{abstract}

Keywords UAV-derived topography $\cdot$ LiDAR $\cdot$ RTK-GPS $\cdot$ SRTM $\cdot$ Hydraulic model · Tropical environment

M. Mazzoleni

maurizio.mazzoleni@geo.uu.se

1 Department of Earth Sciences, Uppsala University, 75236 Uppsala, Sweden

2 Centre of Natural Hazards and Disaster Science (CNDS), Uppsala, Sweden

3 IHE Delft, Institute for Water Education, Delft, The Netherlands

4 Department of Sustainable Development, Environmental Sciences and Engineering, KTH Royal Institute of Technology, Stockholm, Sweden

5 Universidade Eduardo Mondlane UEM, Maputo, Mozambique

6 Salomon Lda, Maputo, Mozambique

7 CONSULTEC Lda, Maputo, Mozambique 


\section{Introduction}

Accounting for more than $40 \%$ of all natural hazards worldwide and half of all deaths caused by natural catastrophes (Ohl and Tapsell 2000), floods have a strong socio-economic relevance. It has been estimated (Jonkman and Vrijling 2008) that in last decade of the twentieth century, floods were responsible for the loss of about 100,000 human lives and affected more than 1.4 billion people worldwide.

The socio-economic impact of flood research has triggered the development of complex hydrological and hydraulic models: one-dimensional (1D) and two-dimensional (2D) hydraulic models, for instance, have become valuable and irreplaceable numerical instruments in floodplain mapping and flood risk assessment (e.g. Aronica et al. 2002).

To be implemented, calibrated and validated hydraulic models require several different input data. One of the most sensitive input data is the geometry of the river channel and floodplain (e.g. Horritt and Bates 2001), usually described through digital elevation models (DEMs).

DEMs can be obtained from different surveying tools and data techniques, ranging from traditional ground surveying to remote sensing techniques applied to air- or spaceborne imagery. Airborne-based light detection and ranging (LiDAR) systems can produce highly accurate and high resolution DEMs, but limited spatial coverage and high costs for data acquisition and processing constrain its application (Sampson et al. 2012; Baugh et al. 2013). The most common space-borne topography data are the shuttle radar topography mission (SRTM) DEM (Hensley et al. 2001) and the advanced spaceborne thermal emission and reflection radiometer (ASTER) DEM (Nikolakopoulos et al. 2006; Zandbergen 2008; Wang et al. 2012).

The increasing availability of distributed remote sensing data has allowed a shift from a data-sparse (and expensive) to a data-rich (and relatively affordable) environment in floodplain modelling (Smith 1997; Alsdorf et al. 2007; Bonnet et al. 2008).

For instance, flood extent maps derived from remote sensing have been widely used to evaluate and compare different hydraulic models (e.g. Horritt and Bates 2001). Nowadays, many flood risk mapping around the world rely on space borne information, topographic data and/or water levels, as remote sensing applications provide support in overcoming lack of ground measured data (Brandimarte et al. 2009). The advances in methodological approaches and techniques to integrate satellite-derived data into hydraulic modelling have highly contributed to reducing uncertainty in floodplain modelling and mapping (Di Baldassarre et al. 2011).

However, SRTM or ASTER-derived DEMs are characterized by low accuracy and high spatial resolution that unavoidably affect the quality of the hydraulic model and flood maps (Casas et al. 2006; Schumann et al. 2008, 2010; Di Baldassarre et al. 2011; Yan et al. 2013; Ali et al. 2015). Moreover, SRTM and ASTER DEMs (and consequent model performance) are also sensitive to preparation methods including vegetation smoothing, hydrological correction algorithms and selection of grid resolution, particularly in remote and low-gradient landscapes (Callow et al. 2007; Wilson et al. 2007; Coe et al. 2008; Baugh et al. 2013; Jarihani et al. 2015).

So, while satellite data are promising for larger river systems and large-scale flood events (e.g. Aplin et al. 1999; Schumann et al. 2007a; Jarihani et al. 2015), their spatial and temporal resolution is not appropriate for small to medium river systems and local scale studies. Also, while high accuracy laser sensing topography has shown reliable results (e.g. Marks and Bates 2000; Sanders 2007), it is affected by high costs, due to 
the need of small planes or helicopters to carry the equipment, which not always justifies its use.

It is inside this gap that unmanned aerial vehicle (UAV) have settled as a tool for imagery collection. Over the last few years, the UAV industry has gone through a quick development, doubling the number of drones flying in the air for civil purposes since 2008 (Colomina and Molina 2014). This growing interest in UAV has triggered research and development in the sector, making it possible to deliver on the market light, precise and easy-to-fly vehicles, carrying different equipment and, most of all, affordable by the public.

The explosion of application of UAV in photogrammetry for topographic measurements is justified by their spatio-temporal field of application, as shown by Siebert and Teizer (2014), and by their lower costs and higher number of points collected as compared to both traditional ground topographic surveys and laser scanning procedures. As Molina et al. (2014) pointed out a big advantage of UAV-derived topography data is their limited uncertainty (up to $\pm 5 \mathrm{~mm}$ ) and high resolution (up to $2 \mathrm{~cm}$ ), which is comparable with terrestrial laser scanning, with a reduction in cost of one order of magnitude and much speeder execution than traditional survey methods.

The main outcome of photogrammetry by UAV is the production of Digital Surface Model (DSM) as UAV measure the elevation of visible objects and not necessarily the bare topography (as provided by DEMs). In most of the cases, fluvial environments can be characterized by the presence of many complex natural and urban features (e.g. vegetation, trees, building, etc.) that intersect the original topography (Sammartano and Spanò 2016). For this reason, one of the major issues of using UAV is the conversion of digital surface models (DSMs) into DEMs where different objects cover the terrain (Bandara et al. 2011). In case of 1D hydraulic modelling, these features may affect the proper flow propagation and drive the model towards unrealistic results. Different methods have been proposed to convert DSM into DEM, e.g. filtering techniques (Badea and Jacobsen 2004), combination of RGB and NIR imagery (Skarlatos and Vlachos 2018) or manual identification of sites corresponding to bare soil. Pichon et al. (2016) found that it can be difficult to retrieve DEM from DSM due to conditions of low visibility of the bare soil in the presence of a permanent cover grass or with full vegetation.

Over the past few years, the use of UAV in hydraulic modelling has received the attention of the scientific community that has started investigating several aspects of UAV photogrammetry in urban and riverine flood modelling. Zinke and Flener (2013) obtained underwater bathymetry data in a Norwegian river from UAV imagery, applying to them an algorithm for coastal bathymetry modelling that relates water depth to its colour radiance. Perks et al. (2016) flew UAV during a flood event of the Alyth Burn in Scotland to capture real-time videos and estimated free surface velocity by tracking the movement of objects in the water. Leitão et al. (2016) used a drone-based DEM for urban surface flow modelling to be potentially connected to a drainage modelling of a Swiss town;

Mourato et al. (2017) developed a Digital Surface Runoff Model from UAV imagery for flood hazard mapping. Şerban et al. (2016) investigated the use of UAV technology coupled with Leica MultiStation to generate a high-quality DEM of the flood-prone area of the he Somessul Mic basin, Transylvania. Recently, Hashemi-Beni et al. (2018) investigated the quality of UAV-based DEM for spatial flood assessment mapping and for evaluating the extent of a flood event in Princeville, North Carolina, highlighting challenges related to on-demand DEM production during a flooding event. Schumann et al. (2019) demonstrated that mapping terrain by means of a UAV has a trivial error compared to LiDAR generated terrain model and can be thus used to extract cross sections with high accuracy. Lee et al. (2019) used UAV of river floodplain to extract detailed topography combining virtual 
reference stations and total station survey equipment in order to reduce a DEM to a true DTM.

All of them have shown promising results for an extensive application of UAV photogrammetry in hydraulic modelling, confirming the advantages of drone-based remote sensing with a drastic cut in risks, costs and execution time, while delivering products of satisfactory quality for the intended use.

Potentialities and challenges of employing UAV in hydraulic modelling have been tested in flood mapping and flood modelling of rivers in European or North American river basins (e.g. Leitão et al. 2016; Mourato et al. 2017; Hashemi-Beni et al. 2018). However, studies on hydraulic modelling supported by drone-derived topographic data in tropical areas are scarce. Nevertheless, in tropical environments, weather conditions like air temperature and wind and difficult logistics in acquiring a high number of ground control points (GCPs) might strongly affect the results of field campaign and thus of the flood modelling. Thus, understanding potentialities and challenges of UAV in flood modelling in tropical areas might show a way forward in flood management in data-poor areas, typically supported by coarse satellite-derived topography because of lack of ground surveyed DEM.

To contribute to filling this gap in the literature, we ran a field campaign to acquire a UAV-derived digital elevation model of a $30 \mathrm{~km}$ stretch of the Mozambican section of Limpopo River near Chokwe. The quality of the UAV-derived DEM has been compared against three other sources of topographic data: LiDAR, SRTM and RTK-GPS data.

Three different hydraulic models were built based on: (1) drone photogrammetryderived DEM $(25 \mathrm{~cm})$, real-time kinematic (RTK) GPS-based topography $(0.5 \mathrm{~m})$ and SRTM DEM topography $(30 \mathrm{~m})$. To assess whether a drone-derived hydraulic model could be a faster and cheaper-to-acquire alternative to a LiDAR-derived model, the performance of each model was tested against the results obtained by a calibrated hydraulic model built on LiDAR DEM $(1 \mathrm{~m})$.

We highlight the potentialities of drone-based hydraulic model and discuss the challenges faced in data acquisition during the flight campaign and point out the limitations and way forward in applying UAV in tropical areas.

\section{Case study and available terrain datasets}

The case study is a 30-km reach of the lower Limpopo River, in the Chokwe district of the Mozambican province of Gaza. Figure 1 shows the extension of the case study and location of the different river cross sections. The upstream boundary of the $30-\mathrm{km}$ reach is represented by the Ponte da Barragem de Macarretane, a barrage with a capacity of $4 \mathrm{~mm}^{3}$ used to elevate the water level to feed the intake of an irrigation channel positioned $1 \mathrm{~km}$ upstream.

The main floodplain area is located on the right bank side of the river, and it is delimited by a discontinuous levee system built after the flood of February 2000, interrupted at some points by pumping systems own by local farmers used to withdraw water directly from the river. On the left bank, near the barrage, rises an 80-m-high hill which, decreasing in a south-east direction, represents a natural obstacle to the water on that side.

Three valuable terrain datasets, having different resolutions and characteristics, were used for testing UAV in flood modelling in the area: (a) light imaging detection and ranging (LiDAR); (b) real-time kinematic (RTK) GPS; and (c) shuttle radar topography mission (SRTM). 

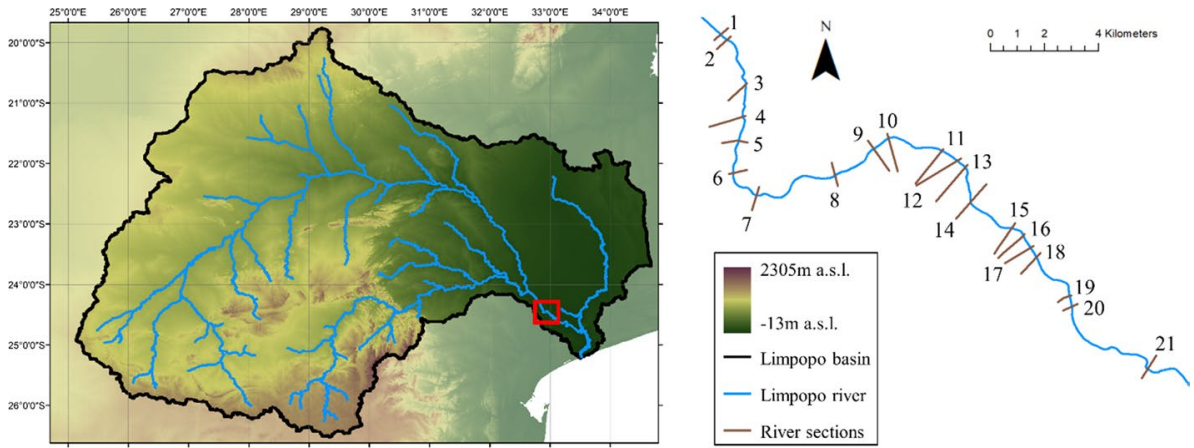

Fig. 1 (left) Geographical location of the case study and (right) locations and names of the river cross sections used for the hydraulic model

LiDAR The LiDAR technique measures the differences in time and wavelength of the returning ray after it is reflected by illuminating a target with ultraviolet, visible or nearinfrared light beam. Because of the different absorbance and reflectance characteristics of different materials, LiDAR can be used to define the real ground also below vegetation (Lillesand et al. 2015). The LiDAR survey over the case study was carried out in 2015 by the National Directorate of Water and Resource Management and the Global Facility for Disaster Reduction and Recovery and has a spatial resolution of about $1 \mathrm{~m}$ and a vertical accuracy between 50 and $60 \mathrm{~cm}$. One of the limitations of LiDAR measurements is the inability to measure topography below the water surface. For this reason, the survey was performed in very low flow conditions, after three consecutive years of drought, which allows for a more accurate characterization of the river bathymetry that is usually under water during uniform flow conditions. In fact, based on the comparison between GPS and LiDAR sections shown in following sections, we can assume that negligible amount of water was present during the LiDAR survey and did not significantly affected model results in this study.

RTK-GPS In the year 2010, a detailed field bathymetric campaign was performed as a joint effort of the National Directorate of Water and Resource Management together with two local consultancy companies, Salomon LDA and Consultec LDA, by means of Total Station and RTK-GPS tools. The objective of the survey was to accurately map the river geometry and build a flood model of the whole Mozambican section of the Limpopo River. The field operations were executed by Salomon LDA using a RTK-GPS guaranteeing a resolution of $0.5 \mathrm{~m}$ and vertical accuracy of about $2 \mathrm{~cm}$, and the outcome was later on used as the main geometry of the 2D HEC-RAS model built for flood management purposes.

SRTM The SRTM mission was initiated by the Space Shuttle Endeavour on February 11, 2000, with the purpose to obtain a near-global high-resolution database of Earth's topography and elevation data using interferometric synthetic-aperture radar (Van Zyl 2001). In 2015, the SRTM data were released to the public with a 1 arc-second sampling corresponding to about $30 \mathrm{~m}$ at the equator. During the data acquisition phase, the interferometric instrumentation induces static and time-varying errors in the wavelength, resulting in an estimated height error that can vary from few centimetres up to more than $10 \mathrm{~m}$. Best performances are achieved in flat areas, while worst ones are associated to forest and vegetated 
areas (like the ones in this study) mainly due to the inability of the radar of penetrating the ground cover (Falorni et al. 2005; Becek 2014). Rodriguez et al. (2006) estimated for SRTM an absolute height error of $5.6 \mathrm{~m}$ for Africa compared to ground control points with an accuracy of $\pm 0.3 \mathrm{~m}$. Similarly, Baade and Schmullius (2016) tested the accuracy of the SRTM for the Kruger National Park, close and particularly similar to our study area, showing absolute errors up to $13.58 \mathrm{~m}$ if compared to RTK ground measurement with $0.02 \mathrm{~m}$ declared accuracy. In this study, the cross sections extracted from the SRTM have an absolute height difference of 5-10 m, when compared to LiDAR, bathymetry and UAV cross sections, in agreement with the results found by Rodriguez et al. (2006) and Baade and Schmullius (2016).

Most importantly, in the following analysis the LiDAR geometry is considered the benchmarking dataset for comparing the other three topographic datasets. The first reason is because the LiDAR topography was retrieved in low flow conditions, which allows a better representation of the complete river sections. The second reason is because the aim of this research is to test UAV-derived topography as an alternative data source for flood risk management to the RTK-GPS data currently used by local engineering companies.

It is worth mentioning that the terrain datasets have been collected over a period of about 15 years; the river stretch has experienced severe flooding during this time, and this might have caused changes in the river morphology and cross section shape. Quantifying the natural evolution in time of the river cross sections is out of the scope of this study, so we based our analysis on the assumption that river geometry is constant in time.

\section{UAV data collection and processing}

\subsection{Field campaign}

The planning phase of the field campaign had the objective to identify the flight areas to accurately define the morphology and elevation of the river bed and river banks, to serve as a crucial input into the hydraulic model.

For this purpose, the location of the RTK-GPS river cross section used in the hydraulic model developed by Salomon LDA and Consultec LDA is used to identify the flight plan areas (see Fig. 2a). Those areas are then sketched in Google Earth and imported in

(a)

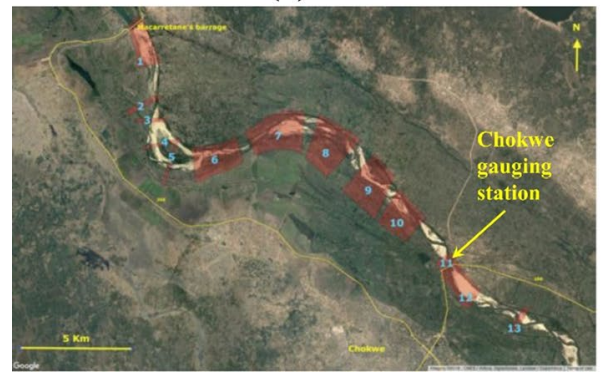

(b)

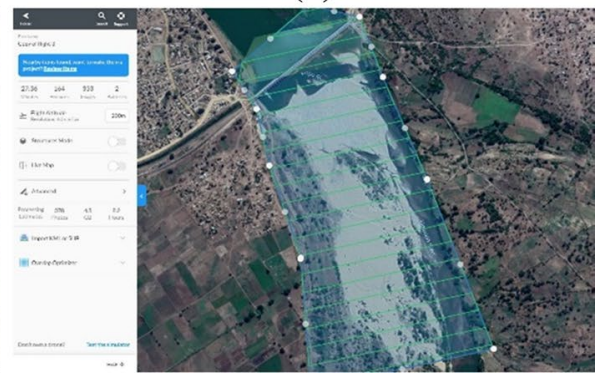

Fig. 2 aLocation of the 13 flight plans covered during the campaign with the UAV; $\mathbf{b}$ example of one of the flight plans in DroneDeploy 
the application DroneDeploy (see Fig. 2b). 13 flight plans of different extent were carried out (see Fig. 2a): due to a long drought in the area, we were able to capture the river bathymetry in some sections.

The drone campaign was carried out in January 2018, in similar low flow conditions than the ones during the LiDAR survey in 2015. Two drones were simultaneously used during the fieldwork campaign: a DJI Phantom 4 Pro (P4Pro) and a DJI Phantom 4 Advanced (P4Adv), each one propelled by mean of 4 electric rotors and equipped with a digital camera stabilised by a mechanical gimbal, GPS/GLONASS positioning systems and on-board computer. The drones carried the same sensor on-board, a 1", SONY Exmor CMOS sensor, with $20 \mathrm{M}$ pixels and a $8.8 \mathrm{~mm} / 24 \mathrm{~mm}(35 \mathrm{~mm}$ format equivalent) lens with FOV of $84^{\circ}$ (Issod 2017). Two tablets (one iPad and one Android based) were used during the survey to automatically fly the drone across the designed areas. We were equipped with a set of 9 batteries, of which 5 were of high capacity and 4 standard, and two charging hubs as shown in Fig. 3a; portable hard-disks were used to store the great number of pictures collected. Figure $3 \mathrm{~b}$ shows an image from the onboard camera.

The quadrotor set-up guarantees high manoeuvrability and small spaces needed for take-off and landing, in exchange of a lower top cruise speed and a smaller ratio between battery usage and area covered. These characteristics proved to be useful in a deeply vegetated area like the banks of the Limpopo.

Based on the characteristics of the camera, we selected a flight altitude of $200 \mathrm{~m}$ and an overlay of $75 \%$ of front-lap and $70 \%$ of side-lap between consecutive images, which resulted in a photograph footprint of about $200 \times 300 \mathrm{~m}$, allowing to capture the same objects in at least 3 images and observed under three different angles (as suggested by Micheletti et al. 2015). Based on this flight characteristics and subsequent processing, we obtained a resolution of roughly $25 \mathrm{~cm}$ per pixel in the photographs and of $24-30 \mathrm{~cm} / \mathrm{px}$ in the final DSM.

Camera settings were manually adjusted before every flight through the app DJI GO. The weather conditions during the surveys were mainly of clear sky with abundance of light through the whole day, so the camera has been set as follow: aperture of $f / 4$ or $f / 5$, ISO between 200 and 400 and shutter speed between 1/1250 and 1/6000, depending on the time of the day and the wind condition at the moment.

The flight plans were then imported in the app DroneDeploy, which automatically manages flight execution and photograph acquisition.

(a)

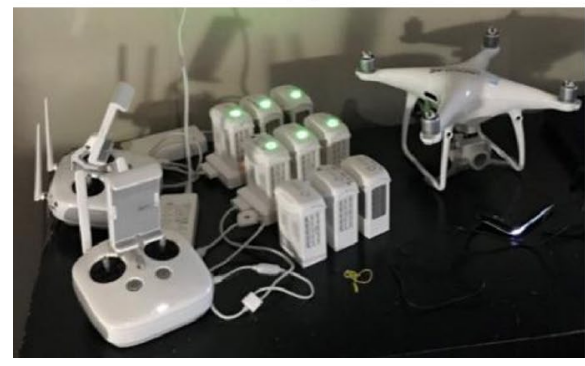

(b)

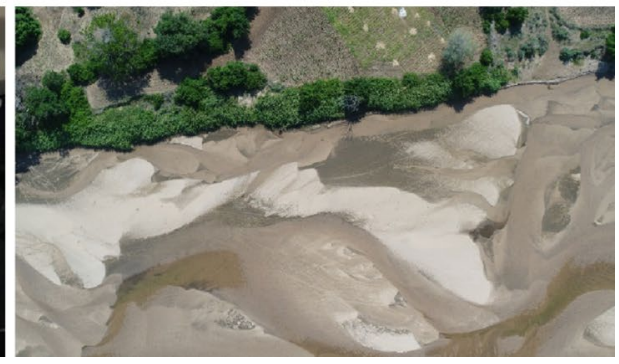

Fig. 3 a DJI Phantom 4 Pro, remote controllers and set of 9 batteries with charging hubs; b example of picture taken from the on-board camera of the DJI Phantom 4Pro 


\subsection{Post-processing of UAV-derived images}

After the field campaigns, we selected the best photographs and input the resulting 35 GB of images in a commercial Structure from Motion (SfM) software, the Agisoft Photoscan Pro version 1.3, and generated orthomosaic and DSM of each flight plan (see an example in Fig. 4).

We followed the workflow recommended by Agisoft Photoscan Pro: (1) we aligned the photographs, building a preliminary sparse point cloud that identifies homologous pixel, using the following settings: accuracy "High", pair preselection "Reference + Generic", key point limit "40,000" tie point limit "4000", adaptive camera model fitting "selected". Bundle adjustments and precise geolocation is also performed at this stage by the software; (2) we densified the sparse point cloud increasing the number of homologous pixels previously defined, using the settings for Build Dense Cloud: quality "high" and depth filtering set to "aggressive"; (3) we generated the DSM from the dense point cloud created during step 2; (4) the orthomosaic was created using the standard settings of Photoscan Pro; and then (5) we exported the DSM and Orthophoto that were used to extract the river cross sections at specific locations perpendicularly to the river channel, starting from one end of the floodplain, continuing over the river banks and flying over the (almost) dry river bed, and ending in the opposite river bank. Finally, (6) the natural features (e.g. trees and bushes indicated in Fig. 5) and water-related noises were automatically identified and filtered from each UAV-based river cross section to then be used in the hydraulic model. In fact, UAVbased DSM includes also vegetation, canopies and other features, since the camera cannot distinguish the ground under a thick canopy.

\subsection{Weather-related issues and bowl effect}

The field campaign was characterized by extreme weather conditions and the appearance of the "bowl effect" in the UAV generated DSM. The case study is located in a tropical area, and during the field campaign the air temperature exceeded 40 degrees in few days, with also the presence of very strong wind. This resulted in major issues for the iPad-equipped

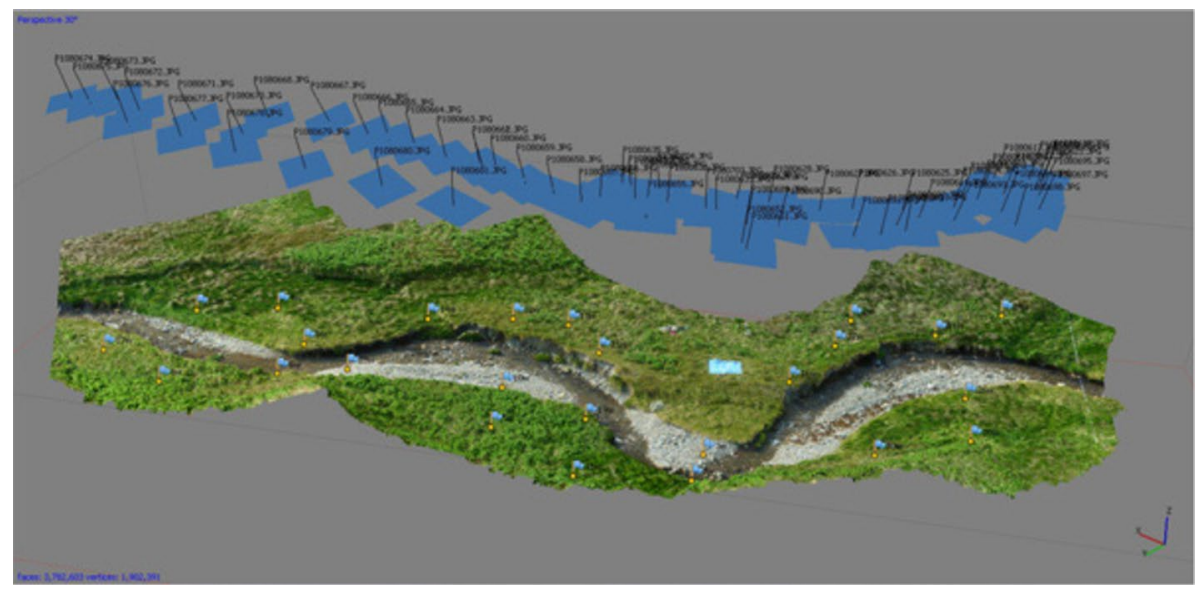

Fig. 4 Orthomoasic derived using Agisoft Photoscan Structure from Motion software, showing the position of the cameras (blue squares floating above the scene) and the location of virtual GCPs used in this flight 


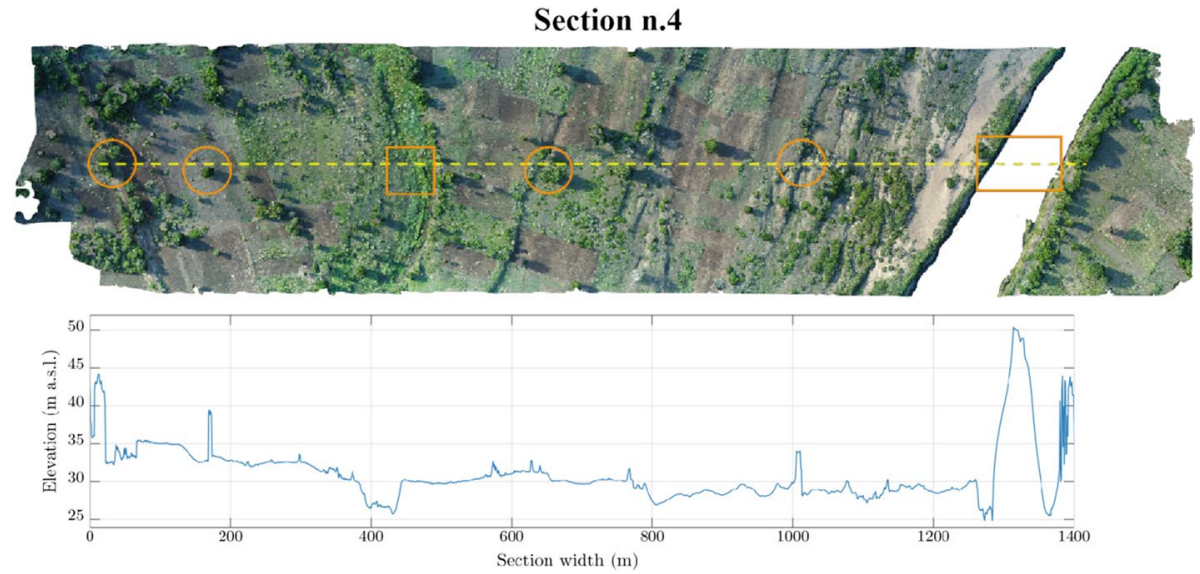

Fig. 5 Representation of the micro-relief features (e.g. trees, bushes) and water-related noises measured by the UAV. In particular, the circles show isolated raising vegetation, while the boxes show pale channel (left side) and high noise induced by the sun reflection on the water surface (right side)

drone, which in few occasions grounded the drone due to overheating, and the UAV compass and on-board GPS signal were also affected by the extreme heat. The UAV Manufacturer, DJI, recommends to use their equipment in between 0 and 40 degrees Celsius (DJI 2009). The high winds prevented the drones from taking off safely and forced us to interrupt the measurements for some hours. Besides this weather-related issue, we experienced a series of problems with the Android-based tablet that had problems related to loss of video communication, failed initiation of flight plans, failed capturing or displaying of images, and other similar problems.

Besides the weather conditions, another main challenge for the estimation of the UAVbased river geometry was due to the bowl (or dome) effect (Wackrow and Chandler 2008), i.e. a fake convex shape at the centre of the river section (see Fig. 6a, b).

This issue is known in the creation of topography from UAV and has received some attention in the literature. According to the studies performed by Nouwakpo et al. (2014), Ouédraogo et al. (2014) and Nesbit and Hugenholtz (2019), the bowl effect can appear if: (1) the density of GCP is not sufficient; (2) the images are all vertical; (3) the flight plans are all parallel one to the other; and (4) the camera calibration models are not correct. However, to the best of our knowledge, there is not yet a published systematic experiment documenting this cause-effect relationship.

One major challenge has been the lack of GCPs due to logistics conditions in the field that did not allow for the acquisition of this crucial dataset. Because of the inability to use Differential or RTK-GPS during the field survey, we relied only and exclusively on the onboard GPS. The absence of GCPs revealed to be a remarkable issue, with a higher impact on large surveying areas rather than on small transects, producing differences between LiDAR and UAV-based section higher than $3 \mathrm{~m}$. This last characteristic is consistent with what reported by James and Robson (2014) on the propagation of the bowl effect from single stereo-pair (a linear strip of photos) to a several-strip image block surveys.

In addition to the lack of GCPs, a main cause of the bowl effect is related to having collected only vertical images, with parallel flight lines only. A solution is represented by the collection of both vertical and oblique photographs and by the use of curved flight lines, so 
(a)

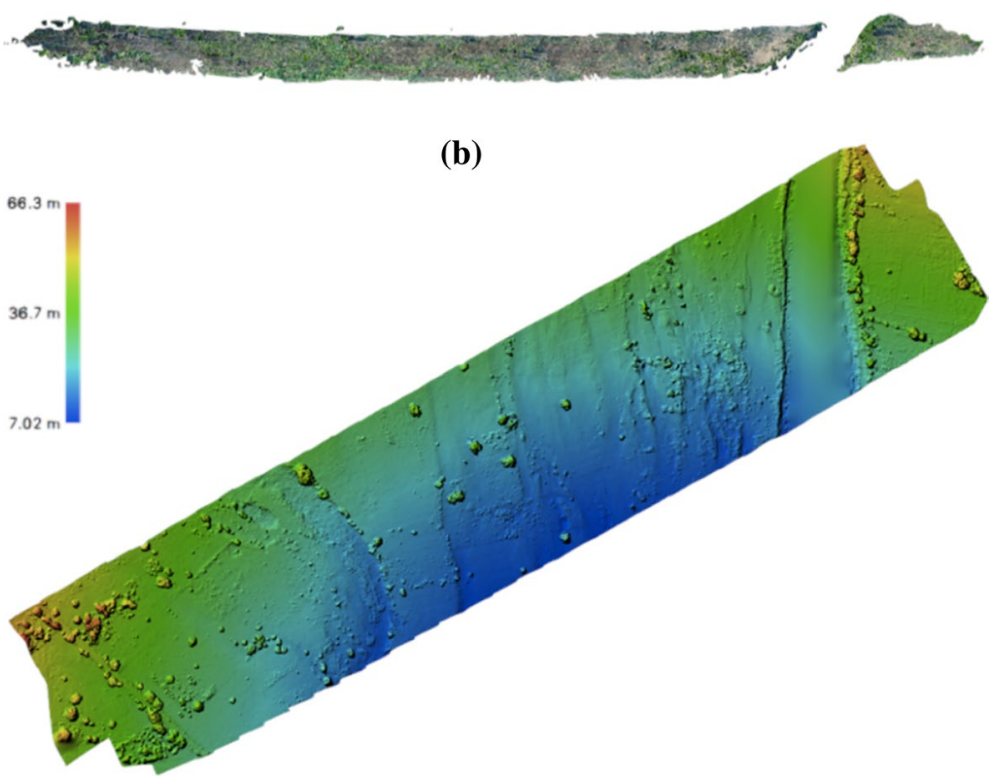

Fig. 6 a Dense cloud of points showing the Bowl effect on UAV derived DEM; b topography elevation in which the blue areas represent the convexity generated by the Bowl effect

to reduce the alignments of images and therefore tie points in the SfM workflow. However, in this study, this was not possible due to the extreme weather conditions which hampered the collection of additional UAV images.

In order to reduce the bowl effect in the affected river sections, we anchored the photogrammetry-derived DSM to virtual GCPs derived from the LiDAR dataset and associate orthophotography. In this way, the photogrammetry-derived DSM was anchored to known positions in post-production. This allowed us to rectify the bowl effect of the UAV data (Fig. 7a, b). A minimum number of Virtual GCPs was selected in order not to bias the UAV DSM towards the already available LiDAR.

Figure 8 shows a comparison between LiDAR, original UAV and modified UAV river section after the automatic filtering for removing vegetation features and water-related noises. Despite an important shift of the left floodplain area, there is still a good agreement between the modified UAV geometry and the LiDAR data, keeping the microtopographic characteristics capture by the UAV. An evident peak can be noticed on the right side of the original UAV section (similarly to Fig. 5). This is a noise induced by sunlight reflection on the main river channel that was removed by the automatic filtering when considering the modified UAV cross section used in the hydraulic model. Moreover, the inclination of the modified UAV section can be associated to the remaining bowl effect that was not completely removed in the post-processing even after including additional GCPs. 
(a)

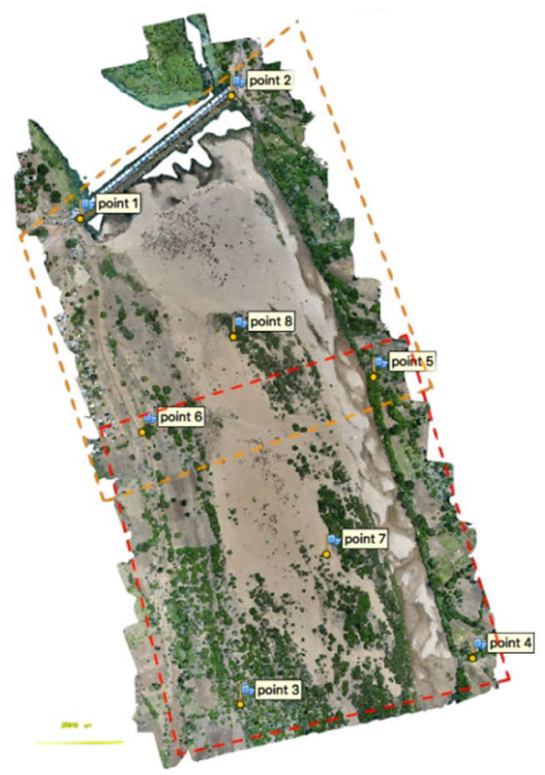

(b)

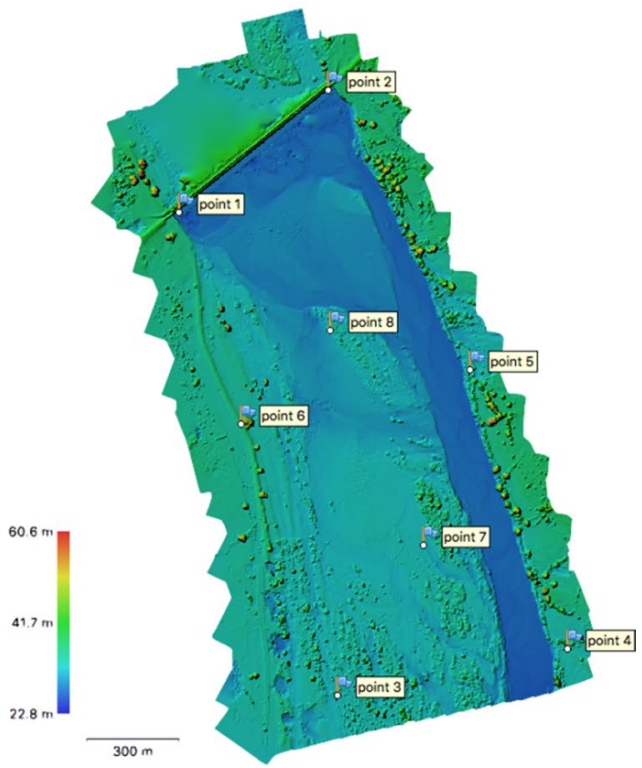

Fig. 7 a Dense cloud of points from the UAV and Location of the selected points to rectify the bowl effect using LiDAR data as GCPs; $\mathbf{b}$ corrected UAV based DSM

Fig. 8 Comparison between LiDAR (black line), original UAV (with bowl effect, microtopographic features and waterrelated noises, dark blue line) and modified UAV geometries adjusted with virtual GCP (orange line) for the river cross section number 4

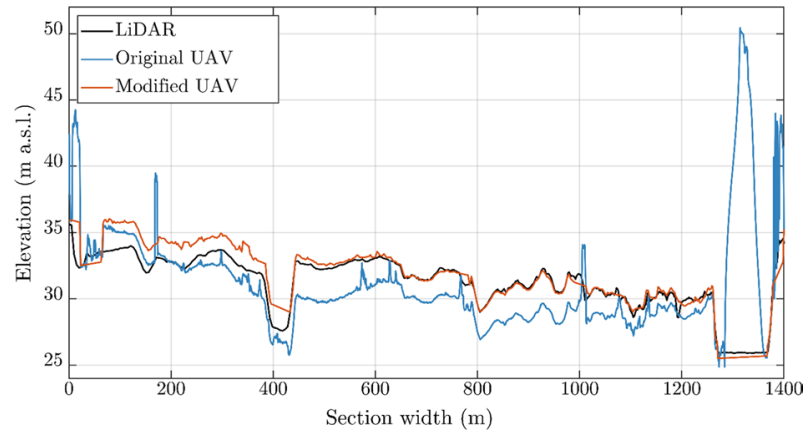

\section{Hydraulic modelling}

The hydraulic model used in this study is the one-dimensional versions of the HECRAS model (HEC Hydrologic Engineering Center 2001) which solves the Saint-Venant equation using the finite-difference method (Preissmann 1961) to discretize the continuity and momentum equations. We selected this model because it requires less computational time compared to more complex model models (Pappenberger et al. 2005). Also, HEC-RAS has been widely used for hydraulic modelling (e.g. Pappenberger et al. 2006; Schumann et al. 2007b; Brandimarte et al. 2009; Di Baldassarre et al. 2009; Mazzoleni et al. 2014). 
The cross section spacing of the hydraulic model developed by Salomon LDA and Consultec LDA (in collaboration with National Directorate of Water and Resource Management) using RTK-GPS river sections, and reported in Fig. 1, is used to extrapolate geometry information from the LiDAR, SRTM and UAV-based terrain data. That is why, the 1D hydraulic models were built considering the geometries of 21 river cross sections available for the different terrain datasets.

The main model parameters were the Manning's coefficient of main river channel $\left(n_{\text {channel }}\right)$ and floodplain ( $\left.n_{\text {floodplain }}\right)$. Model time step was set equal to $1 \mathrm{~h}$. We decided to follow the traditional approach of using a unique value for $n_{\text {channel }}$ and $n_{\text {floodplain }}$ as Liu et al. (2019) showed that the use of distributed floodplain roughness may not necessarily improve model performances. In fact, traditional approach of using two unique values for the channel and floodplain areas yield to similar results compared with distributed Manning's coefficient values.

Because of lack of hydrological data for the upstream boundary conditions, the daily time series of observed river flow at the Chokwe station (see location in Figs. 1 and 2) was considered instead. In particular, in order to test the different terrain datasets in low to medium flow conditions and avoid flow propagation in the floodplain area (which should be modelled using a two-dimensional model), different flood events (see Table 1) with maximum peak ranging between 500 and $1600 \mathrm{~m}^{3} / \mathrm{s}$ were considered as upstream boundary condition. A normal depth of 0.00025 was assumed as downstream boundary condition, as no backwater effect occurs in that part of the river reach.

The parameters of the hydraulic model were estimated considering a seven-months duration flow hydrograph with a maximum peak of $900 \mathrm{~m}^{3} / \mathrm{s}$, observed at the Chokwe's station, as upstream boundary condition. We selected this flood event in order to estimate model parameters for low to medium flow values which are contained within the main river channel. The estimation was performed by minimizing the RMSE between the maximum water surface level at each cross section estimated using LiDAR geometries (assumed as benchmark for our case study) and the simulated water surface levels obtained using RTK-GPS, SRTM and UAV as river geometries.

$$
\operatorname{RMSE}=\sqrt{\frac{1}{T} \sum_{t=1}^{T}\left(y_{t}^{O}-y_{t}^{S}\right)^{2}}
$$

where $y^{O}$ and $y^{S}$ represent the observed and simulated variable of interest (in this case maximum water level) at time step $t$, while $T$ is the total duration of the flood event. The RMSE ranges from 0 (optimal value) to infinite values.

Table 1 Details of flood events used for estimating model parameters and model assessment

\begin{tabular}{lllclll}
\hline & $\begin{array}{l}\text { Parameter } \\
\text { estimation } \\
\text { event }\end{array}$ & $\begin{array}{l}\text { Assessment } \\
\text { event } 1\end{array}$ & $\begin{array}{l}\text { Assessment } \\
\text { event 2 }\end{array}$ & $\begin{array}{l}\text { Assess- } \\
\text { ment } \\
\text { event 3 }\end{array}$ & $\begin{array}{l}\text { Assess- } \\
\text { ment } \\
\text { event 4 }\end{array}$ & $\begin{array}{l}\text { Assess- } \\
\text { ment } \\
\text { event 5 }\end{array}$ \\
\hline $\begin{array}{l}\text { Duration (days) } \\
\text { Average flow } \\
\left(\mathrm{m}^{3} / \mathrm{s}\right)\end{array}$ & 201 & 101 & 81 & 41 & 71 & 121 \\
$\begin{array}{c}\text { Minimum flow } \\
\left(\mathrm{m}^{3} / \mathrm{s}\right)\end{array}$ & 12.5 & 202.8 & 226.7 & 149.4 & 185.6 & 118.1 \\
$\begin{array}{c}\text { Maximum flow } \\
\left(\mathrm{m}^{3} / \mathrm{s}\right)\end{array}$ & 900.3 & 1063.6 & 12.9 & 26.3 & 11.0 & 16.2 \\
\hline
\end{tabular}


The Manning's roughness coefficient values (measured in $\mathrm{s} / \mathrm{m}^{1 / 3}$ ) of the channel and floodplain for LiDAR-based hydraulic model was set equal to 0.03 and 0.07 , respectively, based on the characteristics of the river reach (Chow 2009). A total of 50 different values for $n_{\text {channel }}$ and $n_{\text {floodplain }}$ varying from 0.01 to 0.06 and from 0.05 to 0.11 , respectively, were assumed during the parameter estimation process. A grid-search approach was implemented to find the minims RMSE values generated by the different values of Manning's roughness coefficients. The resulting set of model parameters are reported in Table 2. It is worth noting that because of the low intensity of the flood event used as boundary condition, the results are not sensitive to the different Manning's roughness coefficients for the floodplain area.

In addition to the RMSE, Bias error is also considered as performance measure to assess the goodness of model results with respect to water depth values.

$$
\text { Bias }=\frac{\sum_{t=1}^{T} y_{t}^{S}}{\sum_{t=1}^{T} y_{t}^{O}}
$$

Values of Bias equal to 1 indicates no bias between observations and simulations, while value higher or lower than 1 indicates an overestimation or underestimation respectively.

\section{Results and discussions}

\subsection{Comparison of river geometries}

This section provides a qualitative and quantitative comparison of UAV-, RTK-GPS- and SRTM-derived river geometries using the LiDAR product as benchmark. Table 3 summarizes the characteristics, pros and cons of the four geometries used in this study.

Figure 9 shows a qualitative comparison between the four terrain sources for four river cross sections selected from upstream to downstream with similar distance between each other. A consistent result in our analyses is that SRTM always overestimates both terrain elevation estimated with LiDAR, UAV and RTK-GPS and the river bathymetry due to issue on measuring underwater geometry during normal or high flow conditions. This issue could be the main reason of the systematic overestimation of the river topography by SRTM. In fact, the SRTM data were recorded during a 11-day mission on February 2000, corresponding to a disastrous flood occurred on the Limpopo river, leading to the uncertain assessment of the topography below the extended flooded surfaces by SRTM. Moreover, the lower precision of the spatial data not only affects the degree of detail, but it is also responsible for the vertical misplacement of the cross sections, clearly visible in Fig. 9.

On the other hand, both UAV and LiDAR terrain show similar representation of the river topography, in particular concerning the micro-topographic features next to the main river channel. This could be due to also the similar hydrometereological conditions in which both datasets were retrieved. This similarity should not be a by-product of the coregistration, i.e. the operation of georeferencing one dataset against another one, of UAV with LiDAR because

Table 2 Set of channel and floodplain Manning's parameters for the different terrain datasets

\begin{tabular}{llll}
\hline & RTK-GPS & SRTM & UAV \\
\hline$n_{\text {channel }}$ & 0.043 & 0.015 & 0.023 \\
$n_{\text {floodplain }}$ & 0.057 & 0.097 & 0.090 \\
\hline
\end{tabular}




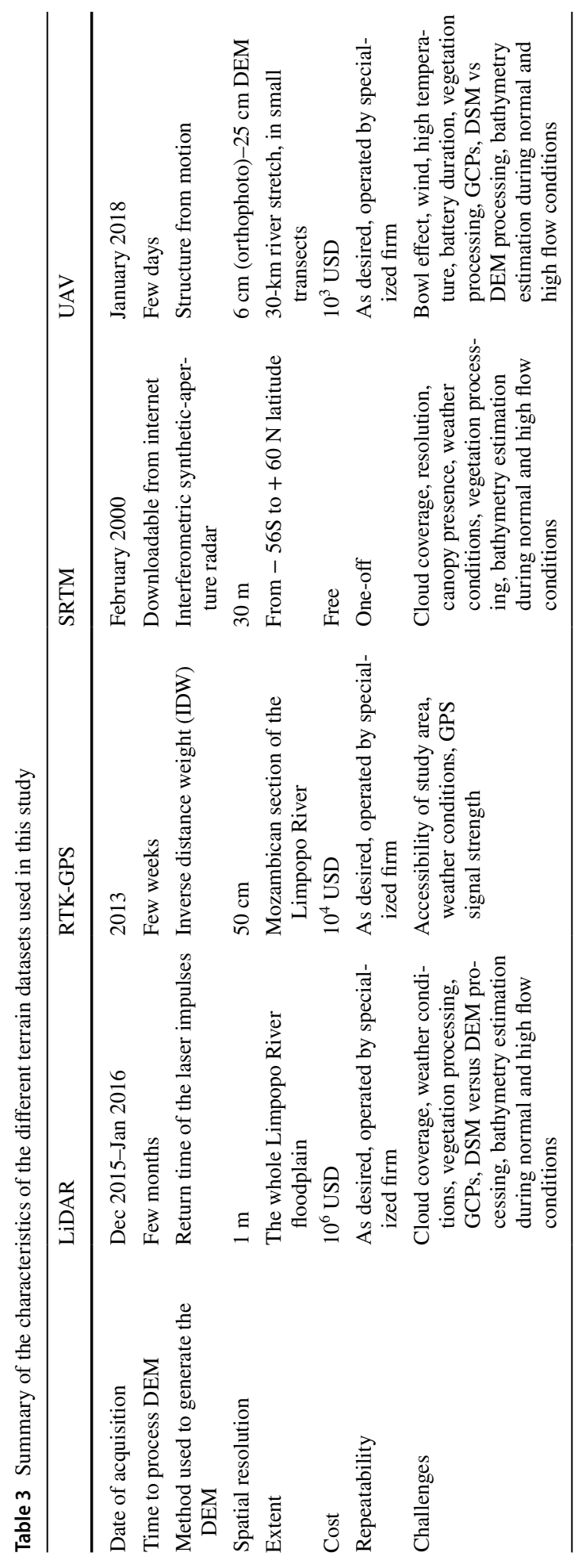



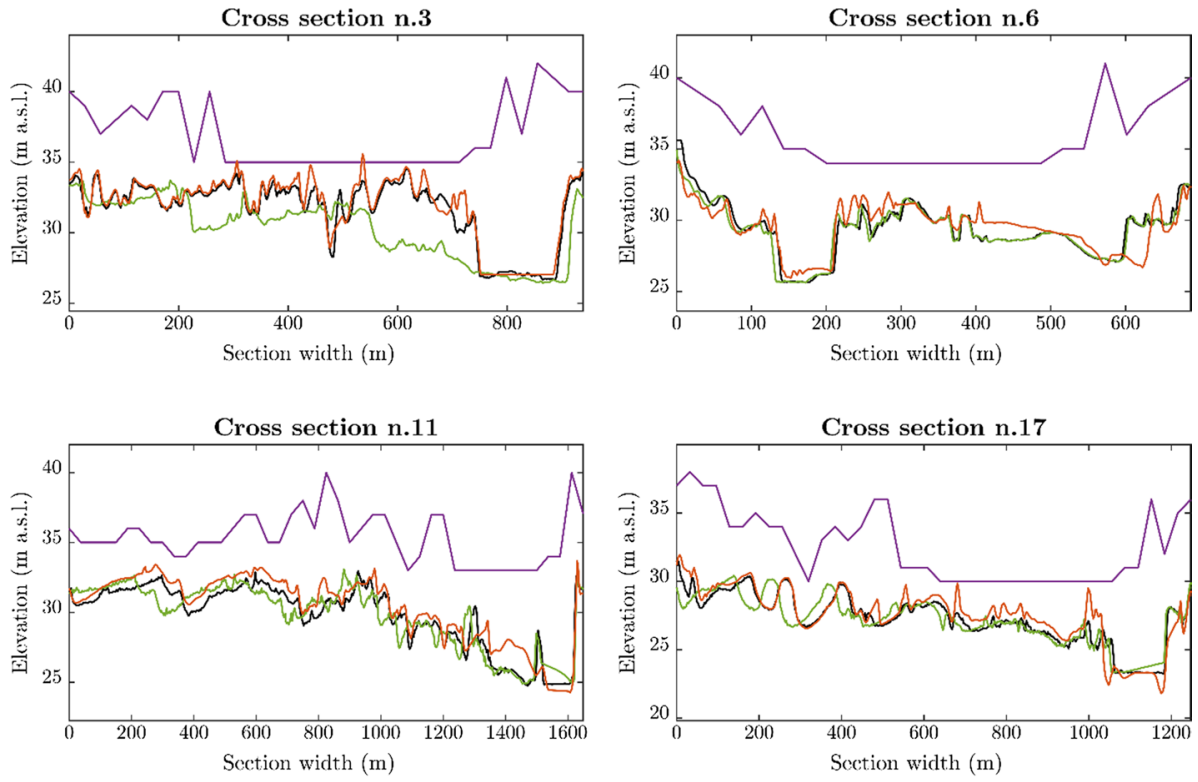

- LiDAR - RTK-GPS - SRTM -UAV

Fig. 9 Comparison between the different datasets and four selected cross sections

this correction affected only the vertical misplacement of the UAV-based terrain and not the micro-topographic features of the river. Similar results are also achieved using RTK-GPS (e.g. sections 6 and 17). The RTK-GPS accuracy and the capacity of properly representing the entirety of the flood plain, including the wetted river bed, make this dataset comparable to the one from LiDAR. Nevertheless, the RTK-GPS tends to underestimate the topographic elevation in the cross section 260055 if compared to the LiDAR and UAV section.

The previous results are related to four specific river cross sections and do not provide an overall picture of the goodness of the different terrain datasets for the entire river reach. For this reason, Fig. 10 represents the RMSE and Bias index, for each river cross section, calculated between the LiDAR geometries (benchmark dataset) and the other terrain products. The results achieved for the entire river reach are in agreement with the ones showed for only four cross sections. As expected, SRTM tends to systematically overestimate the terrain elevation (Bias index always higher than 1) and RMSE values are higher than the ones obtained with RTK-GPS and UAV because of the low degree of detail and accuracy. On the contrary, low RMSE and Bias index values close to one (small bias) are obtained with RTK-GPS and UAV. Overall, RTK-GPS tends to provide more stable Bias index values than the ones achieved with UAV, especially for the downstream cross sections. Similarly, RTK-GPS shows lower RMSE than UAV. It is worth noting that the Bias index values obtained with UAV may be affected by the choice of selecting LiDAR points as correction to solve the bowl effect intrinsic to the UAV measurement. The higher RMSE and Bias values of the UAV geometries in the downstream part of the river reach may be due to the presence of more water in the river bed in the downstream portion of the study area. Moreover, it may be that the LiDAR flight was performed in drier conditions that than during the UAV flight, and therefore, the higher water surface in the UAV may have generated this higher RMSE and Bias. 

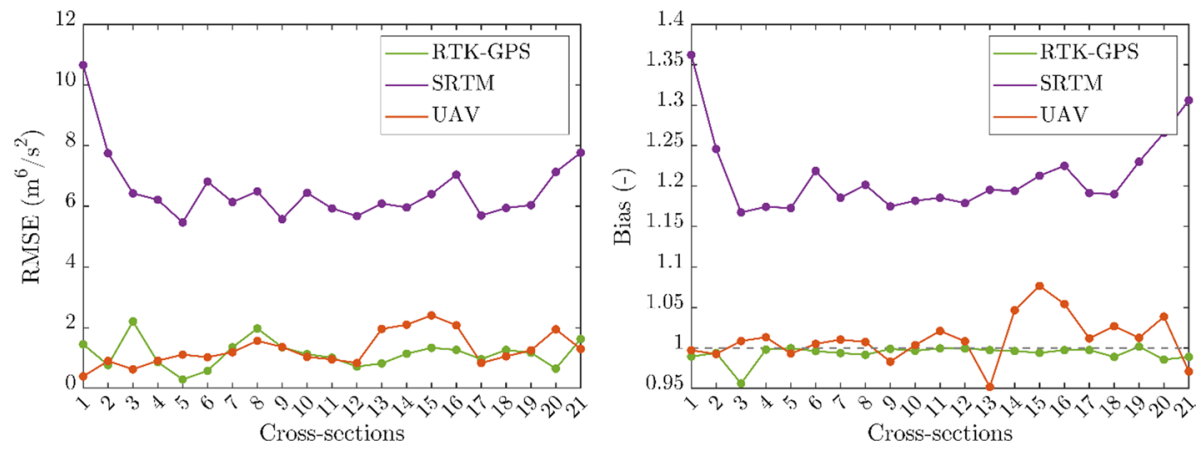

Fig. 10 RMSE and Bias of the cross sections

Figure 11 shows the correlation between thalweg $\left(z_{\min }\right)$ measured from LiDAR, RTKGPS, SRTM and UAV. As already described, SRTM overestimates the $z_{\min }$ for all the river cross sections, while similar low values of RMSE and Bias equal to 1 are obtained for RTK-GPS and UAV. Overall, correlation values close to 1 are obtained for both RTK-GPS and UAV. However, RTK-GPS seems to better represent $z_{\min }$ than UAV, which underestimates $z_{\min }$ values for 12 river cross sections. This can be due to bowl effect occurred with the UAV.

\subsection{Comparison of hydraulic modelling performance}

In order to test the benefit of using UAV-derived river geometries for flood modelling, five flood events having different characteristics in terms of duration and magnitude were used as upstream boundary condition. The flood events were selected so that the flood was mainly contained in the main river channel. Figure 12 shows the boxplots of the RMSE and Bias index between water depths assessed using LiDAR and the other three terrain datasets, along the different cross sections, for the five flood events. A first interesting result is that model results are comparable for the different flood events, demonstrating the robustness of our findings. Overall, the RTK-GPS shows the lowest median values of RMSE values and the lowest variability of RMSE and Bias for the water depth values assessed for the

Fig. 11 Comparison between river thalweg estimate with LiDAR and RTK-GPS, SRTM, UAV

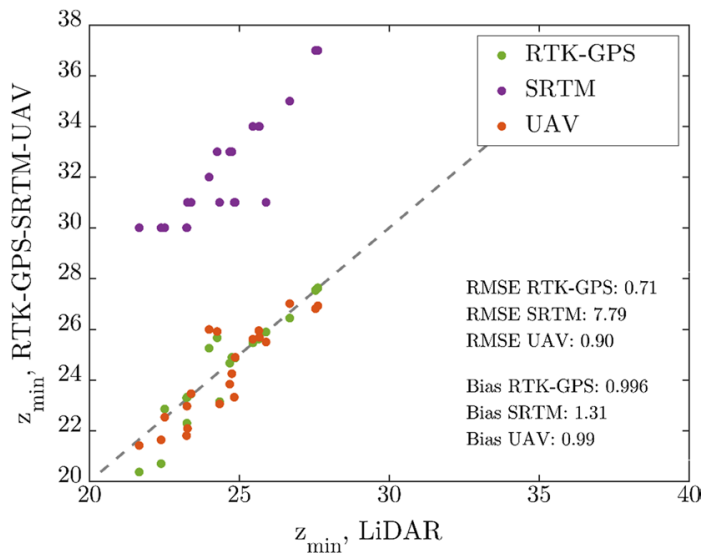


different cross sections. Nevertheless, also UAV-based model results are characterized by low value of RMSE and Bias index close to 1 . However, the variability of the model results for the different cross sections is higher than in case of RTK-GPS data. The largest variability is obtained using SRTM data that tend to consistently underestimate the water depth for all the simulated flood events. This is due to the persistent overestimation of the river topography using SRTM data, which forced the hydraulic model to provide a low value of water depth in order to optimally fit the benchmark water level value from LiDAR data. As a consequence, the optimal Manning's roughness value obtained for the SRTM model is lower than the ones estimated for the other topographies, which results in underestimation of the water depth along the river also during the model assessment process.

The maximum water level profile and the correlation between the maximum water depth obtained with LiDAR geometry and the other datasets at each cross section are represented in Fig. 13. It can be observed that both RTK-GPS and UAV datasets properly represent the maximum water level, while SRTM shows a significant overestimation of the maximum water profile due to overestimation of the river elevation. On the other hand, in order to compensate such elevation overestimation, the model results with SRTM show a significant underestimation of the water depth, as summarized in the scatter plot of Fig. 13.

Model results using RTK-GPS data show an underestimation of the maximum water profile in the upstream part of the river reach, while an overestimation occurs in the downstream part. In case of UAV geometry, Fig. 13 shows the backwater effect generated by the higher riverbed value at the progressive $15 \mathrm{~km}$. In addition, riverbed estimated with UAV shows higher variation than the one of RTK-GPS.

Table 4 summarizes the values of RMSE, Bias index, correlation and $R^{2}$ obtained for the maximum water depth values. The UAV-based model outperforms the one based on RTK-GPS for the estimation of the maximum water depth along the river. In fact, both correlation and $R^{2}$ show substantial higher model performances obtained using
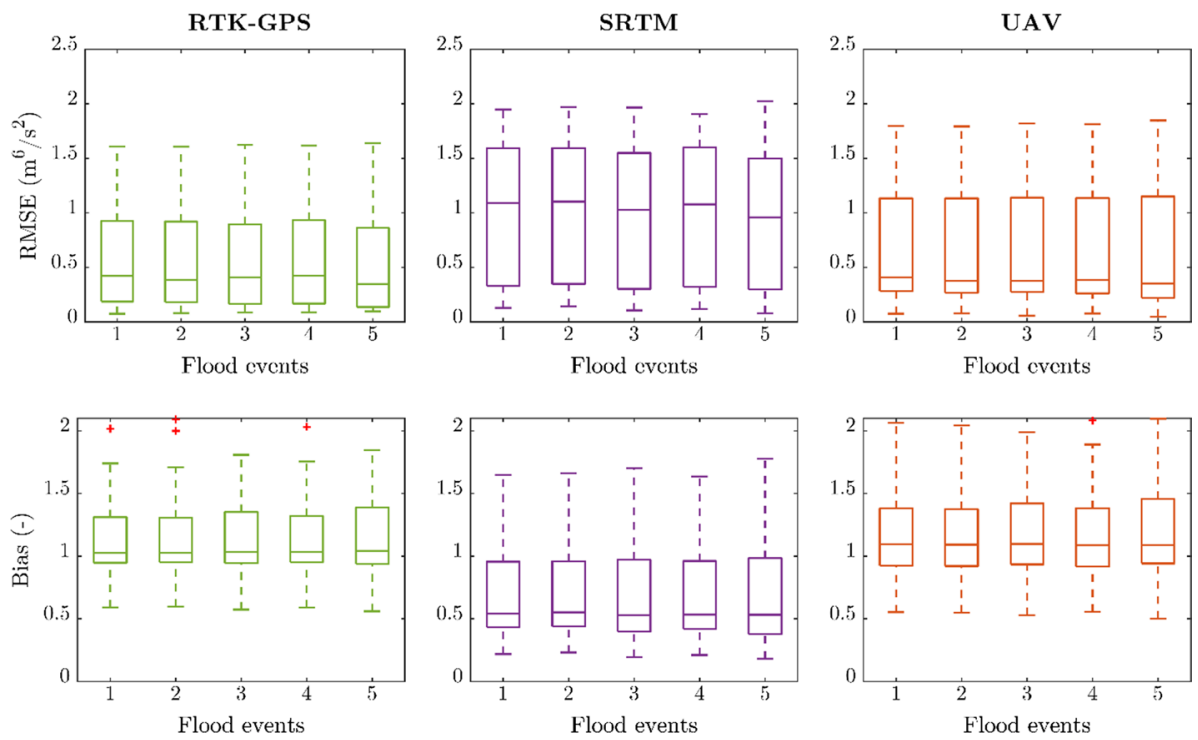

Fig. 12 Boxplots representing the RMSE (first row) and Bias index (second row) between the water depth assessed using LiDAR and the other three terrain datasets (RTK-GPS, SRTM, and UAV) for the five flood events 

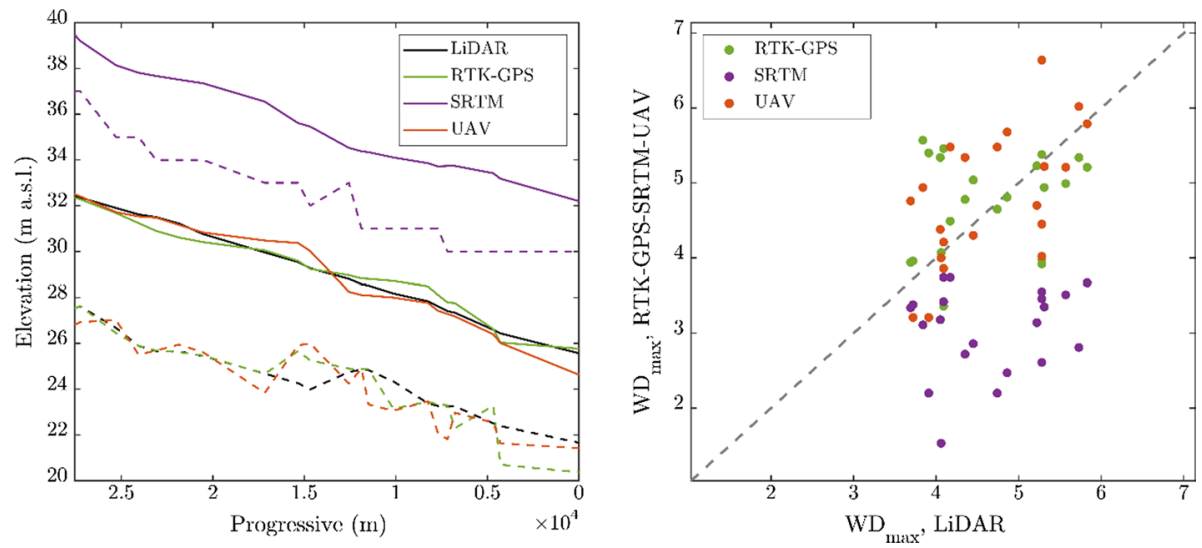

Fig. 13 Left side: Longitudinal profile of the maximum value of water level (continuous line) and minimum river elevation (dashed line) for the four terrain datasets. Right side: Scatter plot of the maximum water depth (WD) values. Both plots are based on the flood event 1 used for model assessment

UAV geometry. In addition, also RMSE with UAV is lower than with RTK-GPS, while the Bias index is comparable. Similar results are achieved also for the other four flood events.

Finally, we compared the maximum water extent at each cross section obtained as a result of the model assessment for the five different flood events and terrain datasets (Fig. 14). Contrary to the results regarding the maximum water depth, the model behaviour for water extent estimation is more variable and a unique conclusion cannot be drawn. However, from the results of Fig. 14 it can be seen that an unreliable estimate of the extent of the flooded area is obtained using SRTM data because of its uncertain DEM and erroneous estimation of topographic features.

Once more, model driven by RTK-GPS and UAV geometries shows comparable results. However, looking at Table 5 it can be noticed that UAV-based model tends again to outperform the RTK-GPS-based model for the estimation of the maximum water extent. In fact, the average values of correlation and $R^{2}$ are higher than the ones of RTK-GPS. Moreover, the maximum water extent estimated using UAV as model geometry shows almost no bias if compared to the LiDAR-based results. On the other hand, RTK-GPS-based model gives RMSE lower than the one based on UAV terrain. This can be due to the similar representation of topographic features between LiDAR and UAV terrains.

Table 4 Summary of the RMSE, Bias index, correlation, $p$ value and $R^{2}$ achieved comparing the maximum water depth for each river cross section of RTK-GPS, SRTM and UAV with the LiDAR geometry for flood event 1

\begin{tabular}{llll}
\hline & RTK-GPS & SRTM & UAV \\
\hline RMSE & 0.83 & 1.80 & 0.75 \\
Bias & 1.02 & 0.66 & 1.03 \\
Correlation & 0.22 & 0.15 & 0.59 \\
$p$ value & 0.33 & 0.51 & 0.01 \\
$R^{2}$ & 0.05 & 0.02 & 0.35 \\
\hline
\end{tabular}



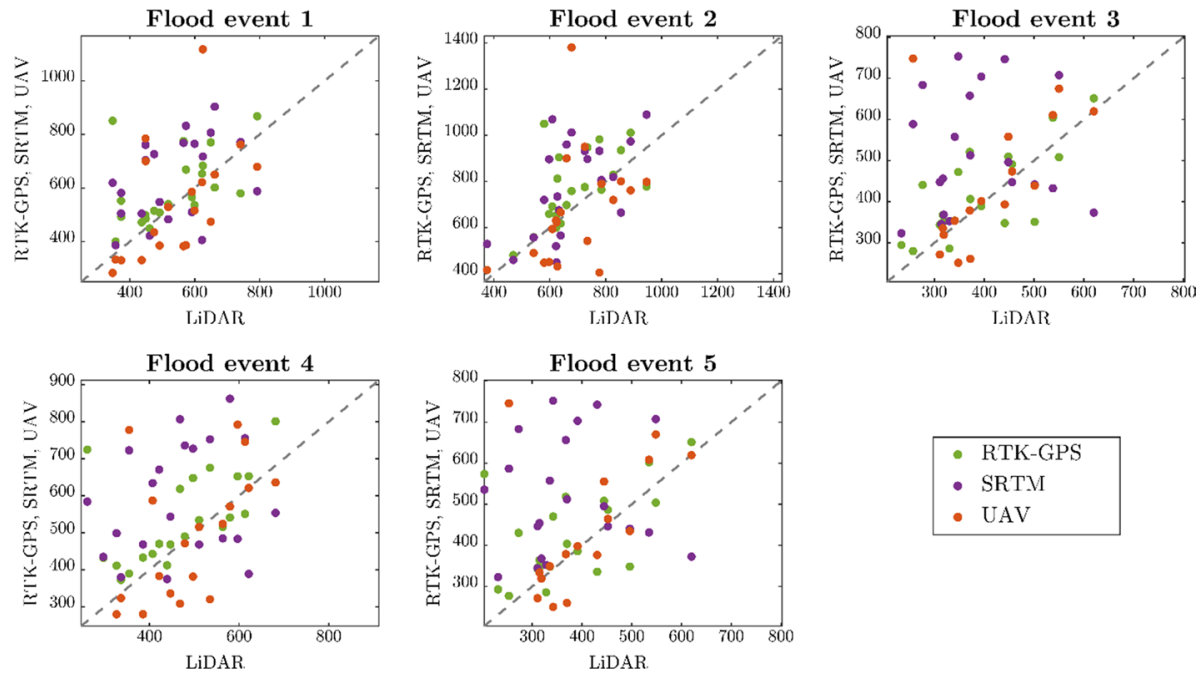

Fig. 14 Scatter plot of the maximum water extent for the different flood events comparing RTK-GPS, SRTM and UAV with LiDAR data

Table 5 Summary of the average value of RMSE, Bias index, correlation, $p$ value and $R^{2}$ achieved comparing the maximum water extend at each river cross section of RTK-GPS, SRTM and UAV with the LiDAR geometry for the 5 flood events

\begin{tabular}{lccr}
\hline & RTK-GPS & SRTM & UAV \\
\hline RMSE & 128.9 & 205.3 & 161.0 \\
Bias & 1.13 & 1.27 & 0.98 \\
Correlation & 0.56 & 0.25 & 0.60 \\
$p$ value & 0.011 & 0.454 & 0.009 \\
$R^{2}$ & 0.32 & 0.11 & 0.36 \\
\hline
\end{tabular}

\section{Conclusions and final remarks}

In this study, we presented the results of testing UAV derived geometry in flood modelling in a tropical environment. The purpose of the research was twofold: (1) to highlight challenges of field campaign and post-processing when investigating a river reach in a tropical environment, exposed to severe weather conditions and influenced by remoteness and wilderness of the study area; (2) to assess the reliability of UAV in reproducing topographic input for hydraulic modelling purposes when compared to other input products, freely available (SRTM) or on-demand (LiDAR and RTK-GPS).

The research is based on planning and executing a field survey with off-the-shelf quadcopter drones and derivation of a DSM through SfM photogrammetry techniques.

Overall, the outcomes of the UAV data analyses are satisfying: the degree of accuracy in the terrain modelling produced errors in the simulated water depth within the tolerances adopted in this typology of studies and comparable in magnitude to the ones obtained from high precision topography models.

Below we summarize the main findings from our experience gained during the field campaign in the lower Limpopo River, which will hopefully be useful for surveys in areas with similar characteristics. 


\subsection{Challenges of field campaign in tropical environment}

Two drones and nine batteries were used to map, in less than 3 days, a total of almost 2500 hectares of terrain on a 30-km-long section of the Limpopo River. During the field campaign, difficulties and risks connected to surveying in a remote area, covered by thick vegetation and populated by wild animals (the Limpopo River is home to snakes, crocodiles, among other), were reduced by manoeuvring the drones by means of remote control from the side of a road (see Fig. 15).

The flight capacity of the UAV used in the survey was limited to an average of $20 \mathrm{~min}$ per each battery, due to strong winds and high temperatures. The paucity of electricity access point in the area for recharging batteries increased the importance of an optimized flight plan and weather conditions proved to be a strong limiting factor. In particular, as the flights took place during the peak of the dry season, in January, temperatures raised above $40{ }^{\circ} \mathrm{C}$, stressing the drone to work outside its operating temperature range. We did not experience malfunctioning of the vehicle during flight operations; however, it affected the use of tablets linked to the remote controllers.

In addition to the aforementioned issues, the lack of GCPs (which compromised the idea of a full remote survey) has generated a significant bowl effect of the surveyed section. The bowl effect (also called dome effect) on DSM generated with SfM photogrammetry is a known feature in recent literature with growing number of studies covering the topic (e.g. Nouwakpo et al. 2014; Ouédraogo et al. 2014; Nesbit and Hugenholtz 2019). Even if most of them are restricted to specific areas or situations, the bowl effect appears to be mainly connected to miscalculations by the photogrammetry software in the spatial relative distances of points captured in overlapping pictures.

In order to restrain the appearance of bowl effect in the final DSM, a well-distributed set of GCPs proved to be fundamental. Unfortunately, in our survey we could not collect GCPs, so we georeferenced our point clouds based on co-registration with the LiDAR flight and corresponding orthophotography, and so we could still assess the quality of the drone's topography generated using off-the-shelf drone equipment.

Moreover, a solution for reducing the bowl effect is represented by the collection of both vertical and oblique photographs and by the use of curved flight lines so as to reduce the alignments of images and therefore tie points in the SfM workflow. However, due to the extreme weather conditions it was not possible to perform additional flights to gather

Fig. 15 Field campaign managed from safe road on the side of the river bank to avoid exposure to wild animals

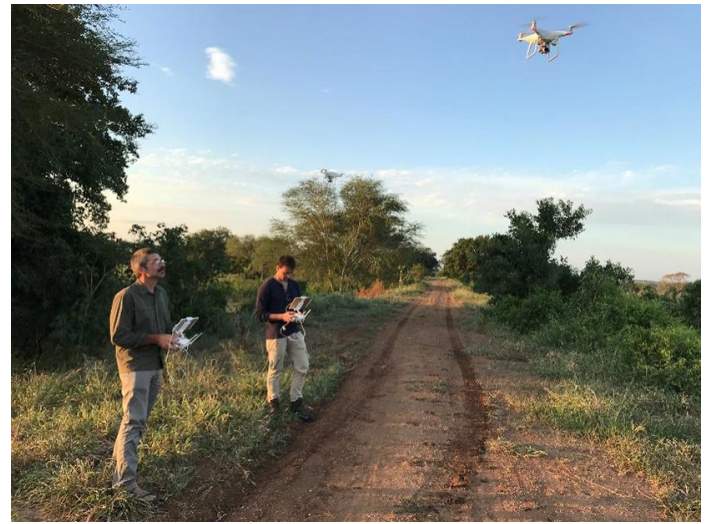


more UAV images and reduce the bowl effect. Another possible solution for reducing the bowl effect in river cross section could be the combination of UAV with additional techniques. For example, other supporting data like RTK-GPS data, GNSS-based solutions as unmanned aquatic vessels equipped with sonar and RTK-GNSS systems, or tethered floating sonar controlled by UAV (Bandini et al. 2018) could be used when UAV is used in remote areas and not GCPs are available.

This study, as well as similar ones, made clear the importance of a well-planned survey, aware of the photographic and photogrammetric process and therefore focused on the acquisition of high quality imagery, since any error in this phase can hardly be solved in post-processing causing imprecisions that will be spread to the hydraulic calculations, magnifying their impact on the final outcome.

\subsection{Assessing performance of UAV derived topography in hydraulic modelling}

Despite the challenges experienced in the field campaign, the UAV derived topographic information showed results that are comparable to the LiDAR and RTK-GPS topographies, especially in the correct representation of micro-topographic features of river geometries. The cross sections extracted from UAV derived DEM followed accurately the shape of those from RTK-GPS and LiDAR, and the residual differences between them can be ascribed to natural changes in the river morphology occurred during the years between the different surveys. RTK-GPS tends to provide less biased results than the ones achieved with UAV, especially for the downstream cross section, when compare to LiDAR geometries. However, during normal and high flow conditions LiDAR- and UAV-based terrain may overestimate river bathymetry as they cannot measure underwater geometries. SRTM extracted cross sections poorly describe the river main channel, but their relevance might grow when the study covers much larger areas.

When testing the different geometries in hydraulic modelling against the simulated water level obtained using LiDAR terrain, model results achieved with five different flood events show comparable values for all geometries, demonstrating the robustness of our findings. Regarding average water depth estimation, RTK-GPS shows the lowest median values of RMSE and the lowest variability of RMSE and Bias index. However, results from UAV-based model also show low median value of RMSE but higher variability for the different cross sections. Similar longitudinal water level profiles can be observed between RTK-GPS and UAV, with water level overestimation on the mid-part of the river and underestimation downstream using UAV-based input. Among all the terrain dataset, SRTM is the one showing highest model error and underestimated simulated water level due to the significant overestimation of river cross section geometries. Interestingly, UAV-based model outperforms the one based on RTK-GPS for the estimation of the maximum water depth and extent along the river. Both correlation and $\mathrm{R}^{2}$ values are significantly higher than the one achieved with RTK-GPS. This can be due to the similar representation of topographic features between LiDAR and UAV terrains.

\subsection{Final remarks}

The results of this and similar studies suggest that the key of a successful use of light commercial UAV for engineering applications resides in the level of automation, robustness and synergy between the phases of data collection and processing. Our experience in the Lower Limpopo shows that this is particularly important in tropical environments, where 
weather conditions strongly affect the operating capacity of the machine and limit the flexibility to adjust flight plans as needed.

The unmanned air system or drone system needs to be intended as a combination of tools for data collection and specific analyses techniques for each intended use. It underlines the importance of combining a solid photogrammetric knowledge with the knowledge of the field of application of drone's derived data, valuable from an engineering point of view. Still, given the innovative nature of these works, there are knowledge gaps that need to be filled by a systematic approach in field data acquisition and data analyses in order to arrive to a consolidated workflow that can harness quality data and information.

During the driest period of the year, drone surveys can be very effective to monitor and quantify morphological changes of river beds and river banks and thus re-calibrate the geometry of the river. The general assessment of drone-based river sections for hydraulic applications is positive and cost-effective when compared to more expensive topographic products such as LiDAR. In addition, the topographic survey campaigns using drones can be easily carried out by Water Resource Management Authorities, every year, after short training activities and needs very little costs for maintenance. In our assessment, there is a high return for the small investment in the drone equipment.

New models of commercial drones with on board RTK-GPS are becoming more frequent also in the price range below 10,000 USD. This, we believe, will create a breakthrough in the ability of having repeated, very accurate and very high resolution, topographic surveys at selected crucial river cross sections, thus allowing improved assessment of high-risk areas. This will be particularly relevant for impervious, remote and data-scarce areas, such our study area, which rely either on expensive ground topographic survey or on low-resolution satellite-derived geometries. Our study has proven that, notwithstanding the challenges of operating UAV in extreme weather conditions, lack of electricity access point and lack of GCPs, the performance of the UAV-based hydraulic model outperforms the poor results of the SRTM-based model and compares to the RTK-GPS-based model.

Acknowledgements Open access funding provided by Uppsala University. This research was partly supported by the IHE-Delftt project Limpopo Flood Study and by European Research Council (ERC) within the project "HydroSocialExtremes: Uncovering the Mutual Shaping of Hydrological Extremes and Society", ERC Consolidator Grant no. 761678, H2020 Excellent Science. Part of this research was also supported by the Swedish Research Council FORMAS, Swedish Strategic research programme StandUP for Energy, and the Centre of Natural Hazards and Disaster Science, CNDS. The authors would like to thank Paulo Sérgio Saveca, Lecturer at ISPG in Gaza Province (Mozambique) for his support during field work.

Open Access This article is licensed under a Creative Commons Attribution 4.0 International License, which permits use, sharing, adaptation, distribution and reproduction in any medium or format, as long as you give appropriate credit to the original author(s) and the source, provide a link to the Creative Commons licence, and indicate if changes were made. The images or other third party material in this article are included in the article's Creative Commons licence, unless indicated otherwise in a credit line to the material. If material is not included in the article's Creative Commons licence and your intended use is not permitted by statutory regulation or exceeds the permitted use, you will need to obtain permission directly from the copyright holder. To view a copy of this licence, visit http://creativecommons.org/licenses/by/4.0/.

\section{References}

Ali AM, Solomatine DP, Di Baldassarre G (2015) Assessing the impact of different sources of topographic data on 1-D hydraulic modelling of floods. Hydrol Earth Syst Sci 19:631-643

Alsdorf DE, Rodríguez E, Lettenmaier DP (2007) Measuring surface water from space. Rev Geophys. https ://doi.org/10.1029/2006RG000197 
Aplin P, Atkinson PM, Tatnall AR et al (1999) SAR imagery for flood monitoring and assessment, pp $557-563$

Aronica G, Bates PD, Horritt MS (2002) Assessing the uncertainty in distributed model predictions using observed binary pattern information within GLUE. Hydrol Process 16:2001-2016

Baade J, Schmullius C (2016) TanDEM-X IDEM precision and accuracy assessment based on a large assembly of differential GNSS measurements in Kruger National Park, South Africa. ISPRS J Photogramm Remote Sens 119:496-508. https://doi.org/10.1016/j.isprsjprs.2016.05.005

Badea D, Jacobsen K (2004) Using break line information in filtering process of a digital surface model. Int Arch Photogramm Remote Sens Spat Inf Sci 34(Part XXX)

Bandara KRMU, Samarakoon L, Shrestha RP, Kamiya Y (2011) Automated generation of digital terrain model using point clouds of digital surface model in forest area. Remote Sens 3:845-858. https://doi. org/10.3390/rs3050845

Bandini F, Olesen DH, Jakobsen J, Kittel CMM, Wang S, Garcia M, Bauer-Gottwein P (2018) Bathymetry observations of inland water bodies using a tethered single-beam sonar controlled by an unmanned aerial vehicle. Hydrol Earth Syst Sci 22(8):4165-4181

Baugh CA, Bates PD, Schumann G, Trigg MA (2013) SRTM vegetation removal and hydrodynamic modeling accuracy. Water Resour Res 49:5276-5289. https://doi.org/10.1002/wrcr.20412

Becek K (2014) assessing global digital elevation models using the runway method: the advanced spaceborne thermal emission and reflection radiometer versus the shuttle radar topography mission case. IEEE Trans Geosci Remote Sens 52:4823-4831. https://doi.org/10.1109/TGRS.2013.2285187

Bonnet M-P, Barroux G, Martinez J-M et al (2008) Floodplain hydrology in an Amazon floodplain lake (Lago Grande de Curuaí). J Hydrol 349:18-30

Brandimarte L, Brath A, Castellarin A, Di Baldassarre G (2009) Isla Hispaniola: a trans-boundary flood risk mitigation plan. Phys Chem Earth Parts A/B/C 34:209-218

Callow JN, Van Niel KP, Boggs GS (2007) How does modifying a DEM to reflect known hydrology affect subsequent terrain analysis? J Hydrol 332:30-39

Casas A, Benito G, Thorndycraft VR, Rico M (2006) The topographic data source of digital terrain models as a key element in the accuracy of hydraulic flood modelling. Earth Surf Process Landf J Br Geomorphol Res Group 31:444-456

Chow VT (2009) Open-channel hydraulics, 30057th edn. The Blackburn Press, Caldwell

Coe MT, Costa MH, Howard EA (2008) Simulating the surface waters of the Amazon River basin: impacts of new river geomorphic and flow parameterizations. Hydrol Process Int J 22:2542-2553

Colomina I, Molina P (2014) Unmanned aerial systems for photogrammetry and remote sensing: a review. ISPRS J photogramm Remote Sens 92:79-97

Di Baldassarre G, Castellarin A, Montanari A, Brath A (2009) Probability-weighted hazard maps for comparing different flood risk management strategies: a case study. Nat Hazards 50:479-496

Di Baldassarre G, Schumann G, Brandimarte L, Bates P (2011) Timely low resolution SAR imagery to support floodplain modelling: a case study review. Surv Geophys 32:255-269

DJI (2009) DJI phantom 4 pro-specs, tutorials \& guides-DJI. In: DJI Official. https://www.dji.com/se/ phantom-4-pro/info. Accessed 7 Feb 2020

Falorni G, Teles V, Vivoni ER et al (2005) Analysis and characterization of the vertical accuracy of digital elevation models from the shuttle radar topography mission. J Geophys Res Earth Surf. https:// doi.org/10.1029/2003JF000113

Hashemi-Beni L, Jones J, Thompson G et al (2018) Challenges and opportunities for UAV-based digital elevation model generation for flood-risk management: a case of Princeville, North Carolina. Sensors $18: 3843$

HEC Hydrologic Engineering Center (2001) Hydraulic reference manual. HEC Hydrologic Engineering Center, Davis

Hensley S, Munjy R, Rosen P (2001) Interferometric synthetic aperture radar (IFSAR). Digital elevation model technologies and applications: the DEM users manual, pp 143-206

Horritt MS, Bates PD (2001) Effects of spatial resolution on a raster based model of flood flow. J Hydrol 253:239-249

Issod CS (2017) Review phantom 4 pro, the fist look-DJI buying guides. In: DJI guides. https://store .dji.com/guides/phantom-4-professional-first-look/. Accessed 7 Feb 2020

James MR, Robson S (2014) Mitigating systematic error in topographic models derived from UAV and ground-based image networks. Earth Surf Proc Land 39:1413-1420. https://doi.org/10.1002/ esp.3609

Jarihani AA, Callow JN, McVicar TR et al (2015) Satellite-derived digital elevation model (DEM) selection, preparation and correction for hydrodynamic modelling in large, low-gradient and data-sparse catchments. J Hydrol 524:489-506 
Jonkman SN, Vrijling JK (2008) Loss of life due to floods. J Flood Risk Manag 1:43-56. https://doi. org/10.1111/j.1753-318X.2008.00006.x

Lee G, Choi M, Yu W, Jung K (2019) Creation of river terrain data using region growing method based on point cloud data from UAV photography. Quat Int 519:255-262. https://doi.org/10.1016/j.quain t.2019.04.005

Leitão JP, Moy de Vitry M, Scheidegger A, Rieckermann J (2016) Assessing the quality of digital elevation models obtained from mini unmanned aerial vehicles for overland flow modelling in urban areas. Hydrol Earth Syst Sci 20:1637-1653. https://doi.org/10.5194/hess-20-1637-2016

Lillesand T, Kiefer RW, Chipman J (2015) Remote sensing and image interpretation. Wiley, Hoboken

Liu Z, Merwade V, Jafarzadegan K (2019) Investigating the role of model structure and surface roughness in generating flood inundation extents using one- and two-dimensional hydraulic models. J Flood Risk Manag 12:e12347. https://doi.org/10.1111/jfr3.12347

Marks K, Bates P (2000) Integration of high-resolution topographic data with floodplain flow models. Hydrol Process 14:2109-2122

Mazzoleni M, Bacchi B, Barontini S et al (2014) Flooding hazard mapping in floodplain areas affected by piping breaches in the Po River, Italy. J Hydrol Eng 19:717-731

Micheletti N, Chandler JH, Lane SN (2015) Investigating the geomorphological potential of freely available and accessible structure-from-motion photogrammetry using a smartphone. Earth Surf Proc Land 40:473-486

Molina J-L, Rodríguez-Gonzálvez P, Molina MC et al (2014) Geomatic methods at the service of water resources modelling. J Hydrol 509:150-162

Mourato S, Fernandez P, Pereira L, Moreira M (2017) Improving a DSM obtained by unmanned aerial vehicles for flood modelling. In: IOP conference series: earth and environmental science. IOP Publishing, p 022014

Nesbit PR, Hugenholtz CH (2019) Enhancing UAV-SFM 3D model accuracy in high-relief landscapes by incorporating oblique images. Remote Sens 11:239

Nikolakopoulos KG, Kamaratakis EK, Chrysoulakis N (2006) SRTM vs ASTER elevation products. Comparison for two regions in Crete, Greece. Int J Remote Sens 27:4819-4838

Nouwakpo SK, James MR, Weltz MA et al (2014) Evaluation of structure from motion for soil microtopography measurement. Photogram Rec 29:297-316

Ohl CA, Tapsell S (2000) Flooding and human health: the dangers posed are not always obvious. $\mathrm{Br}$ Med J Publ Group 321:1167-1168

Ouédraogo MM, Degré A, Debouche C, Lisein J (2014) The evaluation of unmanned aerial systembased photogrammetry and terrestrial laser scanning to generate DEMs of agricultural watersheds. Geomorphology 214:339-355

Pappenberger F, Beven K, Horritt M, Blazkova S (2005) Uncertainty in the calibration of effective roughness parameters in HEC-RAS using inundation and downstream level observations. J Hydrol 302:46-69

Pappenberger F, Matgen P, Beven KJ et al (2006) Influence of uncertain boundary conditions and model structure on flood inundation predictions. Adv Water Resour 29:1430-1449

Perks MT, Russell AJ, Large ARG (2016) Technical Note: Advances in flash flood monitoring using unmanned aerial vehicles (UAVs). Hydrol Earth Syst Sci 20:4005-4015. https://doi.org/10.5194/ hess-20-4005-2016

Pichon L, Ducanchez A, Fonta H, Tisseyre B (2016) Quality of digital elevation models obtained from unmanned aerial vehicles for precision viticulture. OENO One. https://doi.org/10.20870/ oeno-one.2016.50.3.1177

Preissmann A (1961) Propagation des intumescences dans les canaux et rivieres [Propagation of translatory waves in channels and rivers]. In: 1st Congress of the French Association for Computation, Grenoble, France (in French)

Rodriguez E, Morris CS, Belz JE (2006) A global assessment of the SRTM performance. Photogramm Eng Remote Sens 72:249-260

Sammartano G, Spanò A (2016) DEM generation based on UAV photogrammetry data in critical areas. In: GISTAM, pp 92-98

Sampson CM, Fewtrell TJ, Duncan A et al (2012) Use of terrestrial laser scanning data to drive decimetric resolution urban inundation models. Adv Water Resour 41:1-17. https://doi.org/10.1016/j. advwatres.2012.02.010

Sanders BF (2007) Evaluation of on-line DEMs for flood inundation modeling. Adv Water Resour 30:1831-1843

Schumann G, Hostache R, Puech C et al (2007a) High-resolution 3-D flood information from radar imagery for flood hazard management. IEEE Trans Geosci Remote Sens 45:1715-1725 
Schumann G, Matgen P, Hoffmann L et al (2007b) Deriving distributed roughness values from satellite radar data for flood inundation modelling. J Hydrol 344:96-111

Schumann G, Matgen P, Cutler MEJ et al (2008) Comparison of remotely sensed water stages from LiDAR, topographic contours and SRTM. ISPRS J Photogramm Remote Sens 63:283-296

Schumann G, Di Baldassarre G, Alsdorf D, Bates PD (2010) Near real-time flood wave approximation on large rivers from space: application to the River Po, Italy. Water Resour Res. https://doi. org/10.1029/2008WR007672

Schumann GJ-P, Muhlhausen J, Andreadis KM (2019) Rapid mapping of small-scale river-floodplain environments using UAV SfM supports classical theory. Remote Sens 11:982

Şerban G, Rus I, Vele D et al (2016) Flood-prone area delimitation using UAV technology, in the areas hard-to-reach for classic aircrafts: case study in the north-east of Apuseni Mountains, Transylvania. Nat Hazards 82:1817-1832. https://doi.org/10.1007/s11069-016-2266-4

Siebert S, Teizer J (2014) Mobile 3D mapping for surveying earthwork projects using an unmanned aerial vehicle (UAV) system. Autom Constr 41:1-14

Skarlatos D, Vlachos M (2018) Vegetation removal from UAV derived DSMS, using combination of RGB and NIR imagery. ISPRS Ann Photogramm Remote Sens Spat Inf Sci IV- 2:255-262. https:// doi.org/10.5194/isprs-annals-IV-2-255-2018

Smith LC (1997) Satellite remote sensing of river inundation area, stage, and discharge: a review. Hydrol Process 11:1427-1439

Van Zyl JJ (2001) The shuttle radar topography mission (SRTM): a breakthrough in remote sensing of topography. Acta Astronaut 48:559-565

Wackrow R, Chandler JH (2008) A convergent image configuration for DEM extraction that minimises the systematic effects caused by an inaccurate lens model. Photogram Rec 23:6-18

Wang W, Yang X, Yao T (2012) Evaluation of ASTER GDEM and SRTM and their suitability in hydraulic modelling of a glacial lake outburst flood in southeast Tibet. Hydrol Process 26:213-225

Wilson M, Bates P, Alsdorf D, Forsberg B, Horritt M, Melack J, Frappart F, Famiglietti J (2007) Modeling large-scale inundation of Amazonian seasonally flooded wetlands. Geophys Res Lett 34:L15404. https ://doi.org/10.1029/2007GL030156

Yan K, Di Baldassarre G, Solomatine DP (2013) Exploring the potential of SRTM topographic data for flood inundation modelling under uncertainty. J Hydroinform 15:849-861

Zandbergen P (2008) Applications of shuttle radar topography mission elevation data. Geogr Compass 2:1404-1431

Zinke P, Flener C (2013) Experiences from the use of unmanned aerial vehicles (UAV) for river bathymetry modelling in Norway. Vann 48:351-360

Publisher's Note Springer Nature remains neutral with regard to jurisdictional claims in published maps and institutional affiliations. 